\title{
Preferential Loss of Fhit Expression in Signet-Ring Cell and Krukenberg Subtypes of Gastric Cancer
}

\author{
Yu-Ting Chang, Ming-Shiang Wu, Chee-Jen Chang, Pei-Hsin Huang, Su-Ming Hsu, \\ and Jaw-Town Lin
Departments of Internal Medicine (Y-TC, M-SW, J-TL) and Pathology (P-HH, S-MH), National Taiwan University Hospital, and Department of Clinical Research (C-JC), College of Medicine, National Taiwan University, Taipei, Taiwan

\begin{abstract}
SUMMARY: Gastric cancer of youth is predominantly a disease of women, usually of the signet-ring cell subtype, with a predilection for metastasizing to the ovaries. The metastatic ovarian tumor is named a Krukenberg tumor. However, the characteristic genetic alterations between the primary gastric cancer and its metastatic ovarian tumor have not been studied. We used laser capture microdissection to procure tissues from 7 patients with gastric cancer who had ovarian metastases (Krukenberg tumor) and tissues from 14 patients with gastric cancer without ovarian metastases. Loss of heterozygosity (LOH) analysis was performed by use of 16 polymorphic markers, which are mapped to the FHIT, APC, p16, BRCA2, E-cadherin, p53, $B R C A 1$, and DPC4 loci. Immunohistochemical staining with anti-Fhit antibody was performed in 7 Krukenberg tumors and 92 gastric cancers without ovarian metastases. LOH at the FHIT locus was observed in six $(85.7 \%)$ of the seven Krukenberg tumors. In contrast, the gastric cancers without ovarian metastases showed a lower frequency $(28.6 \%, 4 / 14)$ of LOH at the FHIT locus $(p<0.05$, odds ratio $=1 / 15)$. Anti-Fhit antibody showed that expression of Fhit was lost in each of the $7(100 \%)$ Krukenberg tumors but in only $41(44.6 \%)$ of the 92 patients who had gastric cancer without ovarian metastases $(p<0.05$; odds ratio $=$ $1 / 18.614)$. Further analysis showed that loss of Fhit expression is highly associated with signet-ring cell type gastric cancer $(p<$ 0.0001 , odds ratio $=62.5$ ) but is not correlated with prognosis. Alteration of the FHIT gene is a characteristic of signet-ring cell type gastric cancer and Krukenberg tumor. (Lab Invest 2002, 82:1201-1208).
\end{abstract}

$G$ astric cancer is a leading cause of cancer death in the world despite a trend toward decreasing incidence in most countries (Fuchs and Mayer, 1995). Markedly clinical and biologic heterogeneity has been noted among different subtypes of gastric cancer. Gastric cancer consists of intestinal and diffuse subtypes according to Lauren's classification (Lauren, 1965) and can be categorized as signet-ring cell and non-signet-ring cell cancer according to the World Health Organization (WHO) histologic classification (Oota and Sobin, 1990). Different subtypes of gastric cancer differ not only in morphology but also in their clinical and epidemiologic characteristics.

The intestinal subtype of gastric cancer predominates in high-risk populations, is more frequently found in elderly patients, and is characterized by a histologic pattern that mimics large-bowel adenocarcinoma. The diffuse type of gastric cancer is less common, occurring in relatively low-risk populations and mostly in younger individuals or those of blood type A (Wu et al, 1997). Different precancerous lesions probably exist for these two types. The intestinal type of gastric cancer follows the proposed sequential changes from gastritis, intestinal metaplasia, and dys-

DOI: 10.1097/01.LAB.0000028060.37763.D5

Received April 22, 2002.

Address reprint requests to: Dr. Jaw-Town Lin, Department of Internal Medicine, National Taiwan University Hospital, No. 7, Chung-Shan South Road, Taipei, Taiwan.E-mail: jawtown@ha.mc.ntu.edu.tw plasia to cancer. The signet-ring cell subtype of gastric cancer is so named because of the shape of the tumor cells and is characterized by infiltration of individual cells.

Gastric cancer of youth is predominantly a disease of women, especially among Asians (Tamura and Curtiss, 1960). It is usually of the signet-ring cell rather than the gland-forming subtype and has a predilection for metastasizing to the ovaries (Duarte and Llanos, 1981; Holtz and Hart, 1982). When gastric cancer metastasizes to the ovary, the tumor is named a Krukenberg tumor, which is characterized by pleomorphic mucin-filled signet-ring cells accompanied by a sarcomatoid proliferation of the ovarian stroma (Serov et al, 1973). Krukenberg tumors commonly arise in premenopausal women and have a poor prognosis (Gilliland and Gill, 1992; McGill et al, 1999). However, the mechanism by which this particular subtype of gastric cancer metastasizes to the ovaries remains unknown. Recent molecular and epidemiologic studies suggest that different subtypes of gastric cancer have different genetic changes (Tahara, 1993; Wright et al, 1992; Wu et al, 2001). However, the characteristic genetic alterations between the primary gastric cancer and its metastatic ovarian tumor have not been studied.

In this study, we explored the genetic alterations of gastric cancer and its metastatic ovarian tumor by analyzing loss of heterozygosity ( $\mathrm{LOH}$ ) with different microsatellite markers. To avoid stromal cell contamination, we used laser capture microdissection (LCM) 
to procure primary gastric tumor cells and metastatic ovarian tumor cells that were as pure as possible for genetic analysis. Immunohistochemical staining (IHS) of Fhit (fragile histidine triad) protein was preformed in gastric cancers with and without ovarian metastases. We found that LOH at the FHIT locus was observed in the great majority of Krukenberg tumors but infrequently in gastric cancers without ovarian metastases. As expected, loss of Fhit expression was detected in the majority of Krukenberg tumors and in only one half of gastric cancers without ovarian metastases. Alteration of the FHIT gene is a characteristic of Krukenberg tumors and of the signet-ring cell type of gastric cancer.

\section{Results}

The demographic characteristics of the 99 patients are summarized in Table 1. The predominance of female patients and those of young age was noted for Krukenberg tumors. The ages of patients with Krukenberg tumors ranged from 42 to 55 years, with a mean of 45.9 years. In addition, a younger age was observed in the signet-ring cell group, with a mean of 52.4 years, when compared with the non-signet-ring cell group, with a mean of 59.5 years $(p<0.05)$. Nevertheless, although there is a suggestion of female preponderance, the gender difference is not significant between signet-ring cell and non-signet-ring cell groups $(p=$ 0.25) (Table 1).

\section{Heterogeneity and Preferential LOH at the FHIT Locus in Krukenberg Tumor}

LOH affecting the FHIT gene could be observed in six $(85.7 \%)$ of the seven Krukenberg tumors. In contrast, gastric cancers without ovarian metastases demonstrated a lower frequency $(28.6 \%, 4 / 14)$ of $\mathrm{LOH}$ at the FHIT locus $(p=0.024)$ (Table 2). Four cases of Krukenberg tumor (Cases 1, 2, 3, and 7) revealed a discrepancy between primary gastric cancers and metastatic ovarian tumors in the $\mathrm{LOH}$ pattern at the FHIT locus (Table 3). Case 1 had $\mathrm{LOH}$ at a different allele in gastric cancer and metastatic ovarian tumor cells (Fig. 1). Cases 2, 3, and 7 had LOH only in the metastatic ovarian tumors and not in the primary gastric cancers.

\section{Immunochemical Staining for Fhit Expression in Different Subtypes of Gastric Cancer}

To explore the role of FHIT further, we performed IHS with anti-Fhit antibody in the 7 Krukenberg tumors and the 92 gastric cancers without ovarian metastases (Fig. 2). All of the Krukenberg tumors exhibited loss of Fhit expression in both gastric and ovarian tumors (Tables 3 and 4). Only 41 (44.6\%) of the 92 patients who had gastric cancer without ovarian metastases exhibited loss of Fhit expression $(p=0.005$; odds ratio $=1 / 18.614$ ) (Table 4). Loss of Fhit expression was more frequently found in diffuse-type and in mixedtype cancers $(65.0 \%$ and $60 \%$, respectively) than in the intestinal-type cancers $(22.7 \%)(p<0.05)$. There was a significant difference in Fhit expression between intestinal-type cancers and Krukenberg tumors $(p=$ 0.002 ; odds ratio $=1 / 49.286$, with $95 \%$ confidence interval 0.001-0.386). However, no statistically significant difference was observed between Krukenberg tumors and diffuse-type or mixed-type cancers (Table 4).

To clarify whether alteration of Fhit expression is specific for the existence of ovarian metastases of gastric cancer or a specific histologic subtype, we divided the 99 patients (7 Krukenberg tumors and 92 gastric cancers without ovarian metastases) into two groups according to the WHO classification. Eighteen cancers were classified as signet-ring cell subtype, and the remaining 81 belonged to the non-signet-ring cell subtype. All seven Krukenberg tumors belonged to the signet-ring cell subtype. Eighteen (100\%) patients with signet-ring cell type cancer showed loss of Fhit expression, whereas 30 (37\%) patients with nonsignet-ring cell type cancer showed loss of Fhit expression ( $p<0.0001$; odds ratio 62.5 , 95\% confidence interval 3.636-1000) (Table 4). The Fhit expression between signet-ring cell type gastric can-

Table 1. Demographic Characteristics of 99 Patients with Gastric Cancer, Stratified by Histologic Subtype

\begin{tabular}{lrrrr}
\hline & & Age & Sex \\
\cline { 3 - 4 } Gastric cancer & $n$ & Mean (range) & Men:women \\
\hline WHO histologic classification & 99 & $58.2(26-86)$ & $56: 43$ \\
Non-signet-ring cell type & 81 & $59.5(26-86)^{a}$ & $48: 33^{c}$ \\
Signet-ring cell type & 18 & $52.4(33-80)$ & $8: 10$ \\
Krukenberg tumor & 7 & $45.9(42-55)$ & $0: 7$ \\
Gastric cancer without ovarian metastasis & 11 & $56.5(33-80)^{b}$ & $8: 3$ \\
Lauren's classification & 92 & $59.2(26-86)$ & $56: 36$ \\
Intestinal type & 44 & $63.0(26-86)$ & $30: 14$ \\
Diffuse type & 43 & $56.0(33-84)$ & $23: 20$ \\
Mixed type & 5 & $52.4(36-68)$ & $3: 2$ \\
\hline
\end{tabular}

WHO, World Health Organization.

${ }^{a}$ Comparison between non-signet-ring cell type and signet-ring cell type, $p<0.05$.

${ }^{b}$ Comparison between Krukenberg tumor and gastric cancer without ovarian metastasis, $p=0.08$.

${ }^{c}$ Comparison between non-signet-ring cell type and signet-ring cell type, $p=0.25$. 
Table 2. Genetic Alteration of Gastric Cancers with Ovarian Metastases (Krukenberg Tumors) and Without Ovarian Metastases

\begin{tabular}{cccc}
\hline & \multicolumn{3}{c}{ Gastric cancer } \\
\cline { 2 - 3 } $\begin{array}{c}\text { Polymorphic markers } \\
\text { (tumor suppressor genes) }\end{array}$ & $\begin{array}{c}\text { With ovarian metastases } \\
(n=7)\end{array}$ & $\begin{array}{c}\text { Without ovarian metastases } \\
(n=14)\end{array}$ \\
\cline { 2 - 3 } D5S82, D5S346 (APC) & Stomach & Ovary & Stomach \\
D9S1749, D9S1748 $(p 16)$ & 0 & $1 / 6^{a}$ & $1 / 14$ \\
D17S579, D17S855 (BRCA1) & $1 / 6$ & $1 / 6$ & 0 \\
D13S290, D13S310 (BRCA2) & $1 / 6$ & 0 & $1 / 14$ \\
D18S46, D18S65 (DPC4) & $1 / 6$ & 0 & $1 / 14$ \\
D16S421, D16S512 (E-cadherin) & 0 & $1 / 6$ & $2 / 14$ \\
D17S1678, D17S786 (p53) & 0 & 0 & $1 / 14$ \\
D13S1300, D13S4103 (FHIT) & $3 / 7$ & 0 & 0 \\
\hline
\end{tabular}

${ }^{a}$ Number(s) with loss of heterozygosity $(\mathrm{LOH})$ on at least one locus of the two loci/numbers examined by $\mathrm{LOH}$ study.

Table 3. Alteration of FHIT Gene in Krukenberg Tumors, Demonstrated by $\mathrm{LOH}$ Analysis and Immunohistochemical Staining

\begin{tabular}{|c|c|c|c|c|}
\hline \multirow[b]{2}{*}{ Case no. } & \multicolumn{2}{|c|}{$\begin{array}{l}\mathrm{LOH} \text { by } \mathrm{LOH} \\
\text { analysis }\end{array}$} & \multicolumn{2}{|c|}{$\begin{array}{c}\text { Loss of Fhit } \\
\text { protein expression } \\
\text { by IHS }\end{array}$} \\
\hline & Stomach & Ovary & Stomach & Ovary \\
\hline 1 & Yes $^{a}$ & Yes $^{a}$ & Yes & Yes \\
\hline 2 & No & Yes & Yes & Yes \\
\hline 3 & No & Yes & Yes & Yes \\
\hline 4 & No & No & Yes & Yes \\
\hline 5 & Yes & Yes & Yes & Yes \\
\hline 6 & Yes & Yes & Yes & Yes \\
\hline 7 & No & Yes & Yes & \\
\hline
\end{tabular}

${ }^{a} \mathrm{LOH}$ at different alleles in tumors of stomach and ovary in the same case (Case 1).

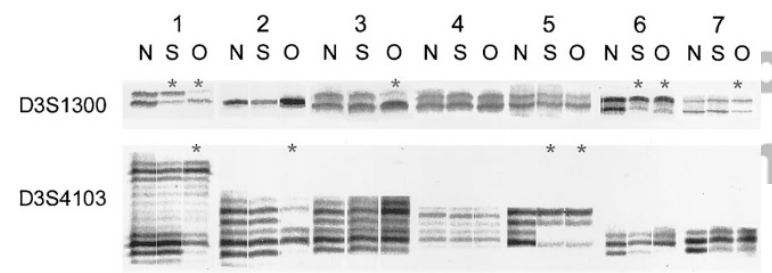

Figure 1.

Illustration of loss of heterozygosity (LOH) at microsatellite loci D3S1300 and D3S4103 in gastric cancer with ovarian metastasis (Krukenberg tumor). $N=$ nontumor gastric tissue; $S=$ primary gastric tumor; $0=$ metastatic ovarian tumor. Asterisks indicate LOH. The residual second band in the cases with $\mathrm{LOH}$ is a result of a small contamination of the samples by the nontumor cells.

cers with and without ovarian metastases was not statistically significant.

\section{Discrepancy Between LOH and IHS in Krukenberg Tumor}

There was no discrepancy between primary gastric cancers and metastatic ovarian tumors in IHS. However, probably because of underestimation of $\mathrm{LOH}$, four cases (Cases 2, 3, 4, and 7) that did not show $\mathrm{LOH}$ at the FHIT locus had loss of Fhit expression by IHS in the gastric tissues. Of the metastatic ovarian tumors, one (Case 4) did not show LOH at the FHIT locus but showed loss of Fhit expression by IHS (Table 3).

\section{Infrequent $\mathrm{LOH}$ at Other Loci}

$\mathrm{LOH}$ was infrequently observed at the APC, p16, p53, BRCA1, E-cadherin, BRCA2, and DPC4 loci in Krukenberg tumors as well as in gastric cancers without ovarian metastases. There was no statistically significant difference in $\mathrm{LOH}$ in these genes between gastric cancer with and without ovarian metastases (Table 2).

\section{Correlation with Fhit Expression and Survival}

Comparing the histomorphologic variables, we found there were no statistically significant differences of survival concerning the histologic subtypes according to the Lauren or WHO classifications. Analysis based on the log-rank test revealed no significant difference in the survival rates between patients with loss of expression of Fhit and those without loss of expression of Fhit (Fig. 3).

\section{Discussion}

Krukenberg tumors are defined as metastatic ovarian adenocarcinomas with a distinctive histologic pattern characterized by signet-ring cell formation (Gilliland and Gill, 1992). The stomach is the most common primary source, accounting for $60 \%$ to $70 \%$ of cases in most reported series (Gilliland and Gill, 1992; Holtz and Hart, 1982; Leffel et al, 1942). Although a host of studies have been conducted on genetic analysis of gastric cancer, the subgroup of Krukenberg tumor and signet-ring cell type gastric cancer has rarely been studied. Moreover, little is known about the genetic changes between the primary gastric tumor cells and the metastatic ovarian ones in Krukenberg tumors. In the English-language literature, only cytogenetic analysis of a Krukenberg tumor cell line, which showed 


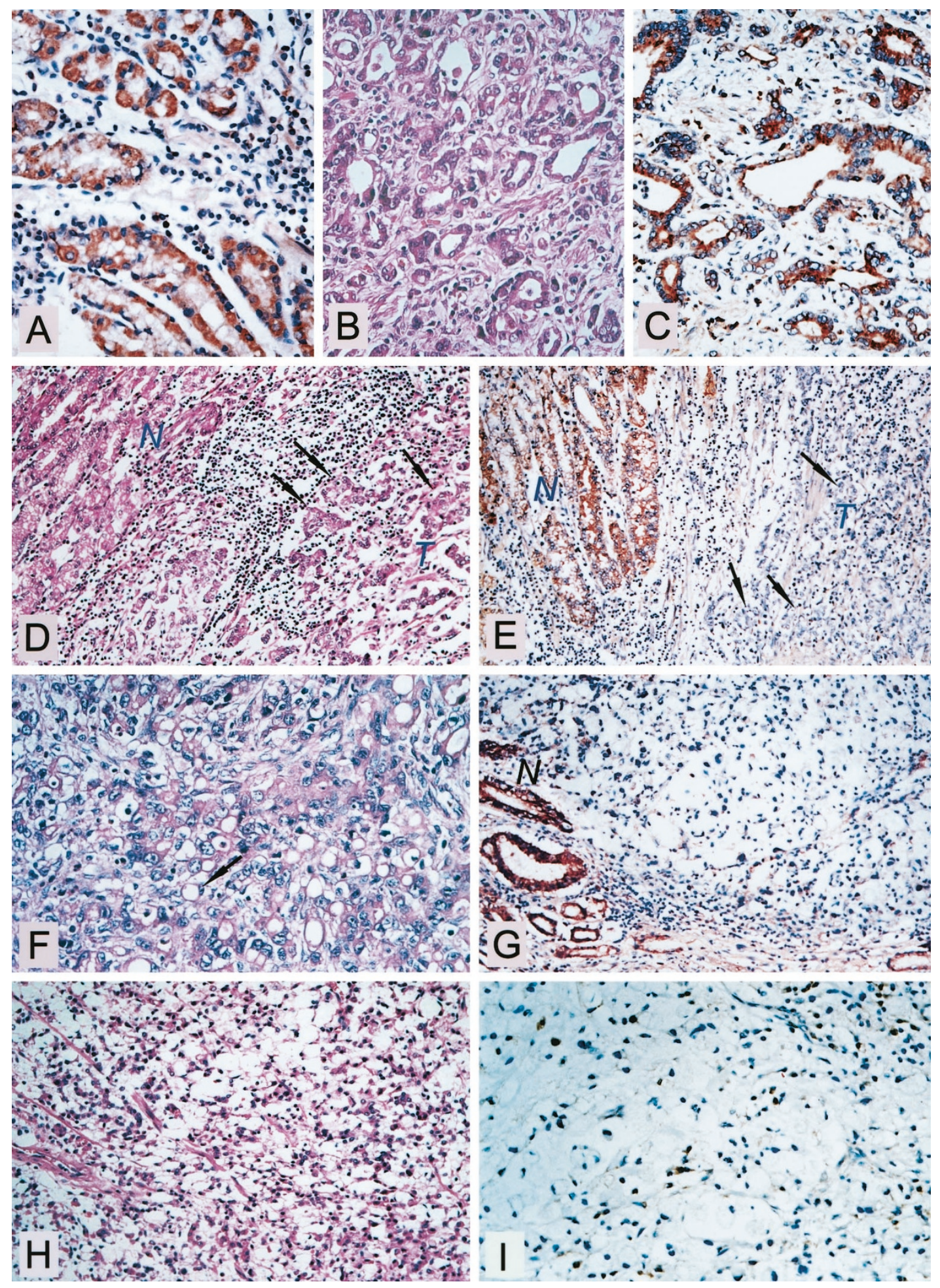

Figure 2.

Histopathology and immunohistochemical staining of Fhit protein in different subtypes of gastric cancer and its ovarian metastasis. Expression of Fhit protein is detected in normal gastric glands ( $A$ ) and also in a case of intestinal type of gastric cancer (B and $C$ ). Loss of Fhit protein expression is seen in a case with diffuse type of gastric cancer ( $\mathrm{D}$ and $\mathrm{E}$ ). Note the expression of Fhit protein in normal glands (labeled $M$ ) but not in the infiltrative tumor area (labeled $T$, arrows). Fhit expression is absent in a case of gastric cancer (signet-ring cell type; $F$ and $G$ ) with ovarian metastasis ( $\mathrm{H}$ and I).

chromosome aberrations involving chromosomes 2 , $3,6,9,11,12$, and 22, has been reported (Sheer et al, 1990; Whelan et al, 1988). Our study is the first disclosing that loss of FHIT is the characteristic ge- netic alteration of Krukenberg tumors and signet-ring cell gastric cancers.

In this study, we noted that $\mathrm{LOH}$ was observed infrequently at seven tumor suppressor gene loci, 
Table 4. Loss of Fhit Protein Expression in Gastric Cancer, Stratified by Ovarian Metastasis and Histologic Classification

\begin{tabular}{|c|c|c|c|c|c|}
\hline \multirow[b]{2}{*}{ Gastric cancer $(n=99)$} & \multicolumn{5}{|c|}{ Loss of Fhit protein expression by IHS } \\
\hline & $\begin{array}{l}\text { Numbers } \\
\text { examined }\end{array}$ & $\begin{array}{c}\text { Numbers with loss } \\
\text { of FHIT protein }\end{array}$ & Frequency & Adjusted odds ratio $(95 \% \mathrm{CI})$ & $p$ value \\
\hline With ovarian metastasis & 7 & 7 & $100 \%$ & 1 & \\
\hline Without ovarian metastasis & 92 & 41 & $44.6 \%$ & $1 / 18.614(0.003-0.968)$ & $0.005^{a}$ \\
\hline Intestinal type & 44 & 10 & $22.7 \%$ & $1 / 49.286(0.001-0.386)$ & $0.0002^{a}$ \\
\hline Diffuse type & 43 & 28 & $65.0 \%$ & 1/8.158 (0.007-2.294) & 0.087 \\
\hline Mixed type & 5 & 3 & $60.0 \%$ & $1 / 10.714(0.003-2.506)$ & 0.152 \\
\hline Signet-ring cell type & 18 & 18 & $100 \%$ & $62.5(3.636-1000)$ & \\
\hline Non-signet-ring cell type & 81 & 30 & $37.0 \%$ & 1 & $p<0.0001^{b}$ \\
\hline
\end{tabular}

$\mathrm{Cl}$, confidence interval.

${ }^{a}$ Compared with gastric cancer with ovarian metastasis (Krukenberg tumor)

${ }^{b}$ Compared with signet-ring cell type.

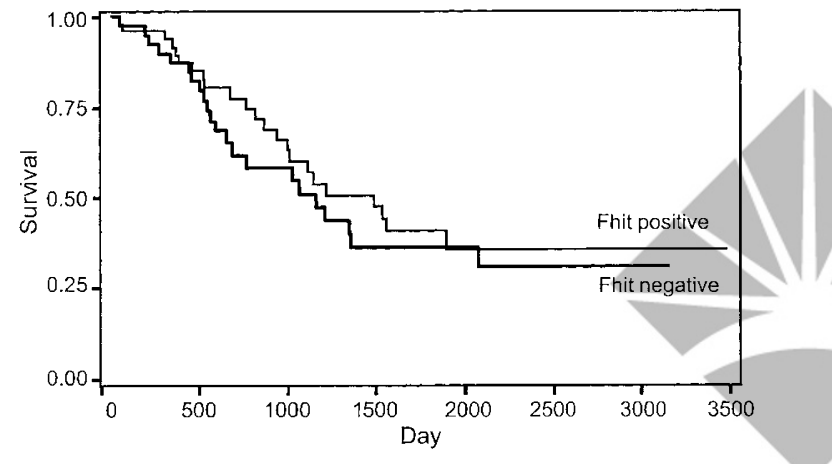

Figure 3.

Survival rates of 99 patients with gastric cancers. There was no significant difference of survival between patients with tumors showed positive and patients with tumors showed negative Fhit expression. Log-rank test: $p=$ 0.48 .

including p53, APC, BRCA1, BRCA2, E-cadherin, p16, and $D P C 4$, in gastric cancer, irrespective of coexisting ovarian metastases. The frequency of mutation at the p53, APC, BRCA1, E-cadherin, and p16 loci was lower than that in previous studies (Sano et al, 1991; Semba et al, 1998; Yokozaki et al, 1997). The low frequency of alteration in these tumor suppressor genes may be a result of the different markers used or a result of underestimation of $\mathrm{LOH}$ with the use of only two selective markers at each gene in this study; the low frequency of alteration could also be a result of different mechanisms such as epigenetic change resulting in silencing of these tumor suppressor genes or simply a result of enrollment of different subgroups of gastric cancer in different studies. However, in this study, there is a significant difference of alteration of FHIT both at the genetic level by microsatellite analysis and at the protein level by IHS between Krukenberg tumors and gastric cancers without ovarian metastases. The result implies that the FHIT gene is crucial in gastric carcinogenesis of Krukenberg tumors.

We have found that the frequency of $\mathrm{LOH}$ at the FHIT locus in ovarian metastatic tumors (six of seven) is higher than in primary gastric cancers (three of seven). This finding was not totally unexpected because accumulation of genetic mutations may occur during cancer progression, and this may account for a higher frequency of genetic change in FHIT in metastatic ovarian tumors. One case (Case 1) in this study had LOH at the FHIT locus both in the primary gastric tumor and in the metastatic ovarian tumor, but at different alleles. This result implied that, in a small number of tumors, acquisition of a genetic mutation or instability might occur separately in the primary cancer and in the metastatic tumor. Alternatively, tumor cells may acquire genetic changes at different alleles early in the progression of the primary tumor, and these cells may differ in their growth rates and biologic behavior (eg, for mutation of ovarian metastases).

All Krukenberg tumors in our study showed parallel changes in Fhit expression by IHS in both gastric and ovarian cancer cells. However, in primary gastric cancers, there seemed to be an increased frequency of loss of Fhit expression in the stomach by IHS. Absence of $\mathrm{LOH}$ at the FHIT locus with loss of Fhit expression in the stomach by IHS may be a result of the underestimation of $\mathrm{LOH}$ when only two markers are used or of the existence of other mechanisms regulating Fhit expression.

Is the alteration of the FHIT gene in Krukenberg tumors a marker of differentiation or a marker of predilection for metastasis to the ovary? The FHIT gene is located at chromosome region 3p14.2 and covers the common human fragile site FRA3B and the $\mathrm{t}(3 ; 8)$ translocation breakpoint in renal cell carcinoma (Ohta et al, 1996). Abnormal FHIT gene expression has been described in lung cancer (Fong et al, 1997; Sozzi et al, 1996b), gastric cancer (Gemma et al, 1997), breast cancer (Negrini et al, 1996), Merkel cell carcinoma (Sozzi et al, 1996a), and head and neck cancer (Mao et al, 1996). The function of the Fhit protein is linked with the metabolism of diadenosine triphosphate (Barnes et al, 1996), which is involved in regulation of DNA replication, signaling of stress responses (Baker and Jacobson, 1997), and cell cycle control (Sard et al, 1999). However, replacement of Fhit protein in human cervical and lung carcinoma cell lines did not suppress tumor cell growth (Otterson et al, 1998). The actual role of the FHIT gene as a tumor suppressor gene remains to be determined. The high 
frequency of alterations involving the FHIT gene at the genomic level could simply be related to the presence of a fragile locus inside the gene, showing the susceptibility to carcinogen-induced alterations.

Several groups of investigators showed that $\mathrm{LOH}$ at the FHIT locus is infrequently (13-16.3\%) found in primary gastric carcinoma and seems not to be correlated with prognosis (Noguchi et al, 1999; Tamura et al, 1997). Others, however, demonstrated that $\mathrm{LOH}$ at the FHIT locus was observed in $42.1 \%$ to $43 \%$ of gastric carcinomas, and the absence of Fhit protein expression was observed in nearly half $(49-67 \%)$ of gastric adenocarcinomas (Baffa et al, 1998; Capuzzi et al, 2000; Gemma et al, 1997). In this study, the overall rate of loss of Fhit expression (48.5\%) was compatible with that in previous studies. We stratified all patients with gastric cancer according to their age, gender, Lauren's classification, and WHO histologic classification to clarify further the attributing factors of FHIT alteration in gastric cancer. Our results show that the loss of Fhit expression in diffuse-type and mixed-type gastric cancers was significantly higher than that of intestinal-type gastric cancer (Table 4). Moreover, the loss of Fhit expression in the signet-ring cell gastric cancer was also significantly higher than that in the non-signet-ring cell type of gastric cancer (Table 4). In addition, the absence of Fhit expression did not correlate with tumor prognosis.

In summary, we have demonstrated the genetic heterogeneity between primary gastric cancer and its ovarian metastasis. We showed that alteration of the FHIT gene is a characteristic of signet-ring cell type gastric cancer and Krukenberg tumor. This finding allows one to delineate further how expression of the FHIT gene may be linked to the differentiation of different subtypes of gastric cancer.

\section{Materials and Methods}

\section{Specimens}

By searching through the pathology records of the National Taiwan University Hospital from 1995 to 2000 , we identified seven patients who fulfilled the WHO diagnostic criteria for Krukenberg tumor. As a control, 92 consecutively selected gastric cancers without ovarian metastases were identified. Their demographic features were retrieved from the medical records.

\section{LCM and DNA Extraction}

A Pixcell LCM system (Acturus Engineering, Inc., Mountain View, California) was used for microdissection of frozen sections and paraffin-embedded sections of primary gastric cancer cells, nontumor gastric tissues, and metastatic ovarian tumor tissues. Serial sections of $10-\mu \mathrm{m}$ thickness were mounted on a silicon-coated slide and incubated sequentially in $70 \%$ ethanol (60 seconds), hematoxylin (30 seconds), $70 \%$ ethanol (30 seconds), $95 \%$ ethanol (30 seconds), eosin (10 seconds), 95\% ethanol (twice, 30 seconds each), and $100 \%$ ethanol (30 seconds), followed by two final rinses in xylene (5 minutes each). The resultant sections were subjected to LCM, for which the amplitude and pulse duration of the Pixcell laser were adjusted to allow complete tissue capture with a $60-\mu \mathrm{m}$ laser beam. The amplitude was set at $50 \mathrm{~mW}$ and the duration at $55 \mathrm{msec}$. After dissection, the thermoplastic film-coated cap containing the captured tissue was scraped into an Eppendorf tube containing $200 \mu \mathrm{l}$ of digestion buffer $(10 \mathrm{~mm}$ Tris- $\mathrm{HCl}$ containing $200 \mu \mathrm{g} / \mathrm{ml}$ proteinase $\mathrm{K}, 1 \mathrm{~mm}$ EDTA, and 1\% Tween 20 ) and incubated in a water bath at $37^{\circ} \mathrm{C}$ overnight. Thereafter, the samples were heated at $95^{\circ} \mathrm{C}$ for 10 minutes to inactivate proteinase $\mathrm{K}$. The extracted genomic DNA was stored at $-20{ }^{\circ} \mathrm{C}$ until further analysis.

\section{LOH Analysis}

DNAs from 7 trios of nontumor tissue, primary gastric tumor, and metastatic ovarian tumor of Krukenberg tumors and 14 pairs of nontumor tissue and gastric cancers without ovarian metastases were subjected to $\mathrm{LOH}$ analysis by use of 16 different polymorphic markers. These markers were mapped to potential tumor suppressor gene loci such as FHIT (D3S1300, D3S4103), APC (D5S82, D5S346), p16 (D9S1748, D9S1749), BRCA2 (D13S290, D13S310), E-cadherin (D16S421, D16S512), p53 (D17S786, D17S1678), BRCA1 (D17S579, D17S855), and DPC4 (D18S46, 18S65).

For PCR, $5 \mu$ l of extracted genomic DNA was amplified in a volume of $15 \mu \mathrm{l}$, containing $1 \times \mathrm{PCR}$ reaction buffer $(50 \mathrm{~mm} \mathrm{KCl} / 10 \mathrm{~mm}$ Tris- $\mathrm{HCl}, \mathrm{pH} 9.0$, containing $1.5 \mathrm{mM} \mathrm{MgCl}_{2}, 0.01 \%[\mathrm{w} / \mathrm{v}]$ gelatin, $1 \%$ Triton $\mathrm{X}-100,2.5 \mu \mathrm{M}$ dATPs, $75 \mu \mathrm{M} \mathrm{d}(\mathrm{G}+\mathrm{T}+\mathrm{C}) \mathrm{TPs}$, $0.033 \mu \mathrm{Ci} / \mu \mathrm{l}\left[\alpha^{33} \mathrm{P}\right] \mathrm{dATP}, 12 \mu \mathrm{M}$ of 5 -end and 3 -end primers, and $0.6 \mathrm{U}$ of TaqDNA polymerase; Pro Tech Enterprise Co. Ltd., Taipei, Taiwan). The reaction mixture was overlaid with mineral oil. The samples were amplified with a PTC-100 Programmable Thermal Controller (MJ Research, Inc., Watertown, Massachusetts) as follows: denaturation for 30 seconds at $94^{\circ} \mathrm{C}$; reannealing for 30 seconds at $55^{\circ} \mathrm{C}$ for D5S82 and D18S46 and at $58^{\circ} \mathrm{C}$ for D13S290, D13S310, $\mathrm{D} 17 \mathrm{~S} 579$, and D17S855 and at $60^{\circ} \mathrm{C}$ for the other markers; elongation for 45 seconds at $72^{\circ} \mathrm{C}$. After 35 cycles of amplification, the PCR products were denatured, cooled on ice, loaded onto $6 \%$ polyacrylamide gels, electrophoresed, dried, and exposed to x-ray films.

\section{Immunohistochemistry}

IHS of Fhit protein was performed on all 7 Krukenberg tumors and on the 92 gastric cancer tissues. Briefly, $5-\mu \mathrm{m}$ sections from representative tissue blocks were cut and mounted on sialine-coated sides, deparaffinized in xylene, and then rehydrated in distilled $\mathrm{H}_{2} \mathrm{O}$ through graded alcohols. Antigen retrieval was enhanced by microwaving of slides in citrate buffer $(\mathrm{pH}$ 6.0) for 10 minutes. Endogenous peroxidase activity 
was quenched by incubation with $6 \%$ hydrogen peroxide in methanol. Slides were then incubated with primary rabbit polyclonal anti-Fhit antibody (ZP44; Zymed Laboratories Inc., South San Francisco, California) at a dilution of 1:300 overnight at $4^{\circ} \mathrm{C}$. Slides were washed three times in PBS and then incubated with a biotinylated goat anti-rabbit secondary antibody for 10 minutes at room temperature. Antigenantibody complexes were detected with the avidinbiotin-peroxidase method, with diaminobenzidine used as a chromogenic substrate. Tissue sections were lightly counterstained with hematoxylin and then examined by light microscopy. We scored the results of IHS as negative if more than $95 \%$ of tumor cells were unstained.

\section{Statistical Analysis}

The demographic characteristics of these 99 patients were analyzed by the Wilcoxon rank-sum test and by $\chi^{2}$ test when appropriate. Comparisons of $\mathrm{LOH}$ at the FHIT locus and Fhit expression between Krukenberg tumors and gastric cancers without ovarian metastases were performed with Fisher's exact test. Analyses of survival were performed using the Kaplan-Meier method, and the differences between the patient groups were tested by the log-rank test. Prognostic relevance was verified by applying Cox regression analysis. A $p$ value less than 0.05 is considered to indicate statistical significance. The odds ratio and its confidence interval are also presented.

\section{References}

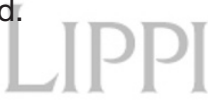

Baffa R, Veronese ML, Santoro R, Mandes B, Palazzo JP, Rugge M, Santoro E, Croce CM, and Huebner K (1998). Loss of FHIT expression in gastric carcinoma. Cancer Res 58: 4708-4714.

Baker JC and Jacobson MK (1997). Alteration of adenyl dinucleotide metabolism by environmental stress. Proc Natl Acad Sci USA 94:2350-2352.

Barnes LD, Garrison PN, Siprashvili Z, Guranowski A, Robinson AK, Ingram SW, Croce CM, Ohta M, and Huebner K (1996). FHIT, a putative tumor suppressor in humans, is a dinucleoside $5^{\prime}, 5^{\prime \prime}-\mathrm{P} 1, \mathrm{P} 3$-triphosphate hydrolase. Biochemistry 35:11529-11535.

Capuzzi D, Santoro E, Hauck WW, Kovatich AJ, Rosato FE, Baffa R, Huebner K, and McCue PA (2000). Fhit expression in gastric adenocarcinoma: Correlation with disease stage and survival. Cancer 88:24-34.

Duarte I and Llanos O (1981). Patterns of metastases in intestinal and diffuse types of carcinoma of stomach. Hum Pathol 41:237-242.

Fong KM, Biesterveld EJ, Virmani A, Wistuba I, Sekido Y, Bader SA, Ahmadian M, Ong ST, Rassool FV, Zimmerman PV, Giaccone G, Gazdar AF, and Minna JD (1997). FHIT and FRA3B 3p14.2 allele loss are common in lung cancer and preneoplastic bronchial lesions and are associated with cancer-related FHIT cDNA splicing aberrations. Cancer Res 57:2256-2267.

Fuchs CS and Mayer RJ (1995). Gastric carcinoma. N Engl J Med 333:32-41.
Gemma A, Hagiwara K, Ke Y, Burke LM, Khan MA, Nagashima M, Bennett WP, and Harris CC (1997). FHIT mutations in human primary gastric cancer. Cancer Res 57:14351437.

Gilliland R and Gill PJ (1992). Incidence and prognosis of Krukenberg tumor in Northern Ireland. Br J Surg 79:13641366.

Holtz F and Hart WR (1982). Krukenberg tumors of the ovary: A clinicopathologic analysis of 27 cases. Cancer 50:24382447.

Lauren $P$ (1965). The two histological main types of gastric carcinoma: Diffuse and so-called intestinal type carcinoma. Acta Pathol Microbiol Scand 64:62-65.

Leffel JM, Masson JC, and Dockerty MB (1942). Krukenberg tumors: Survey of 44 cases. Ann Surg 115:102-113.

Mao I, Fan YH, Lotan R, and Hong WK (1996). Frequent abnormalities of FHIT, a candidate tumor suppressor gene, in head and neck cancer cell lines. Cancer Res 56:5128-5131.

McGill FM, Ritter DB, Rickard CS, Kaleya RN, Wadler S, Greston WM, and O'Hanlan KA (1999). Krukenberg tumors: Can management be improved? Gynecol Obstet Invest 48: 61-65.

Negrini M, Monaco C, Vorechovsky I, Ohta M, Druck T, Baffa R, Huebner K, and Croce CM (1996). The FHIT gene at 3 p14.2 is abnormal in breast carcinomas. Cancer Res 56: 3173-3179.

Noguchi T, Muller W, Wirts HC, Willers R, and Gabbert HE (1999). FHIT gene in gastric cancer: Association with tumour progression and prognosis. J Pathol 188:378-381.

Ohta M, Inoue H, Cotticelli MG, Kastury K, Baffa R, Palazzo J, Siprashvili Z, Mori M, McCue P, Druck T, Croce CM, and Huebner K (1996). The FHIT gene, spanning the chromosome $3 p 14.2$ fragile site and renal carcinoma-associated $t(3 ; 8)$ breakpoint, is abnormal in digestive tract cancers. Cell 84: 587-597.

Oota K and Sobin LH (1990). Histological typing of gastric and oesophageal tumors. International Histological Classification of Tumors, 18. Geneva: World Health Organization.

Otterson GA, Xiao GH, Geradts J, Jin F, Chen WD, Niklinska W, Kaye FJ, and Yeung RS (1998). Protein expression and functional analysis of the FHIT gene in human tumor cells. J Natl Cancer Inst 90:426-432.

Sano T, Tsujino T, Yoshida K, Nakayama H, Haruma K, Ito H, Nakamura Y, Kajiyama G, and Tahara E (1991). Frequent loss of heterozygosity on chromosomes $1 \mathrm{q}, 5 \mathrm{q}$, and $17 \mathrm{p}$ in human gastric carcinomas. Cancer Res 51:2926-2931.

Sard L, Accornero P, Tornielli S, Delia D, Bunone G, Campiglio M, Colombo MP, Gramegna M, Croce CM, Pierotti MA, and Sozzi G (1999). The tumor-suppressor gene FHIT is involved in the regulation of apoptosis and in cell cycle control. Proc Natl Acad Sci USA 96:8489-8492.

Semba S, Yokozaki H, Yasui W, and Tahara E (1998). Frequent microsatellite instability and loss of heterozygosity in the region including BRCA1 (17q21) in young patients with gastric cancer. Int J Oncol 12:1245-1251.

Serov SF, Scully RE, and Sobin LH (1973). Histological typing of ovarian tumors. No. 9. Geneva: World Health Organization, 17-19. 
Sheer D, Gorman PA, Whelan R, and Hill BT (1990). Cytogenetic analysis of a cell line established from a Krukenberg tumor. Cancer Genet Cytogenet 46:71-74.

Sozzi G, Alder H, Tornielli S, Corletto V, Baffa R, Veronese ML, Negrini M, Pilotti S, Pierotti MA, Huebner K, and Croce CM (1996a). Aberrant FHIT transcripts in Merkel cell carcinoma. Cancer Res 56:4871-4875.

Sozzi G, Veronese ML, Negrini M, Baffa R, Cotticelli MG, Inoue H, Tornielli S, Pilotti S, Gregorio LD, Pastorino U, Pierotti MA, Ohta M, Huebner K, and Croce CM (1996b). The FHIT gene at 3p14.2 is abnormal in lung cancer. Cell 85:1726.

Tahara E (1993). Molecular mechanism of stomach carcinogenesis. J Cancer Res Clin Oncol 119:265-272.

Tamura G, Sakata K, Nishizuka S, Maesawa C, Suzuki Y, Iwaya T, Terashima M, Saito K, and Satodate R (1997). Analysis of the fragile histidine triad gene in primary gastric carcinomas and gastric carcinoma cell lines. Genes Chromosomes Cancer 20:98-102.

Tamura PY and Curtiss C (1960). Carcinoma of the stomach in the young adult. Cancer 13:379-385.
Whelan R, Gibby E, Sheer D, Povey S, and Hill BT (1988). Characterization of a continuous cell line in culture established from a Krukenberg tumor of the ovary arising from a primary gastric adenocarcinoma. Eur $\mathrm{J}$ Cancer Clin Oncol 24:1397-1408.

Wright PA, Quirke P, and Attanoos R (1992). Molecular pathology of gastric carcinoma: Prognosis and prospects. Hum Pathol 23:848-859.

Wu MS, Chang MC, Huang SP, Tseng CC, Sheu JC, Lin YW, Shun CT, Lin MT, and Lin JT (2001). Correlation of histologic subtypes and replication error phenotype with comparative genomic hybridization in gastric cancer. Genes Chromosomes Cancer 30:80-86.

Wu MS, Yang KC, Shun CT, Hsiao TJ, Lin CC, Wang HP, Chuang SM, Lee WJ, and Lin JT (1997). Distinct clinicopathologic characteristics of diffuse- and intestinal-type gastric cancer in Taiwan. J Clin Gastroenterol 25:646-649.

Yokozaki H, Kuniyasu H, Semba S, Yasui W, and Tahara E (1997). Molecular bases of human stomach carcinogenesis. In: Tahara E, editor. Molecular pathology of gastroenterological cancer. Tokyo: Springer-Verlag, 55-70.
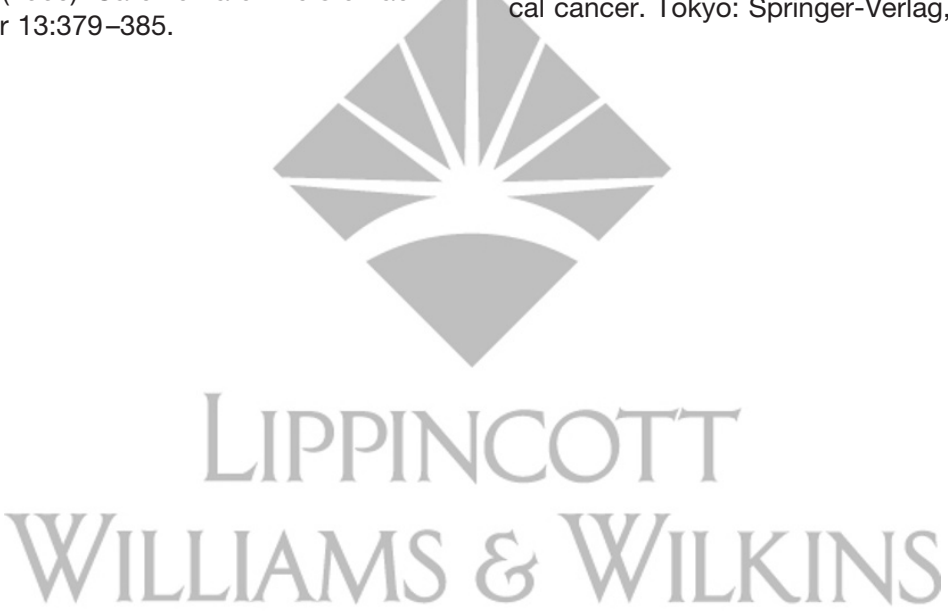